\title{
A social work study on relationship between socio-economic factors and mental health
}

\author{
Zeinab Kamrani $^{\mathbf{a}^{*}}$ and Abdullah Shafiabadi ${ }^{\mathrm{b}}$
}

${ }^{a}$ Masters Student, Department of Counseling, Marvdasht Branch, Islamic Azad University, Marvdasht, Iran

${ }^{b}$ Department of Counseling, Allameh Tabatabaie University, Tehran, Iran

\section{H R O N I C L E}

Article history:

Received December 2, 2013

Accepted 8 May 2014

Available online

June 12014

Keywords:

Mental health

Socio-economic factors

Social work study

\section{A B S T R A C T}

\begin{abstract}
This paper presents a social work study to investigate the effects of employees' income and age on their mental health. The study has accomplished among a sample of 150 randomly selected employees who worked for Esfahan steel company located in city of Esfahan, Iran. The study uses a standard questionnaire, which is adopted from Goldberg and Williams (2000) [Goldberg, D., \& Williams, P. (2000). General health questionnaire (GHQ). Swindon, Wiltshire, UK: NFER Nelson.]. The results of the implementation of ANOVA test have revealed that while there was a significant and positive relationship between employees' salary and mental health, there was not any meaningful relationship between employees' age and mental health.
\end{abstract}

(C) 2014 Growing Science Ltd. All rights reserved.

\section{Introduction}

During the past fifty years, there have been many discussions on work conditions, quality of life, etc. and several researchers have suggested that quality of life could be influenced by various factors in work conditions (Levinson, 1962; Baba et al., 1999; Brackbill et al., 2013). Quality-of-life assessment studies changes in physical, mental, and social health to make evaluate the human and financial expenses as well as advantages of new programs and interventions (Robbins, 2001). Kamrani and Shafiabadi (2014) investigated the relationship between quality of life and mental health among selected regular employees who worked for Esfahan Steel Company, Iran. In their study, they reported a meaningful relationship between quality of work life and mental health. However, there appeared to be no meaningful relationship between mental health and other quality of life components such as human relations, job security, job progress, working in partnership, dignity, balancing work and life, work commitment and financial status.

*Corresponding author.

E-mail addresses: zeinb1350@yahoo.com (Z. Kamrani) 
Ghodrati and Zargarzadeh (2013) performed a study on the relationship between employee mental health and agility strategic readiness in a case study of Esfahan hospitals in Iran. The study tried to find out whether enhancing organizational agility and mental health of staff could increase strategic readiness for crises or not. They reported that working conditions as well as employees' mental health were in good conditions and the employees with higher levels of mental health had higher readiness to deal with potential crises.

Ahmadi et al. (2012) investigated the relationship between job performance and employees' mental health in one of Iranian natural gas refinery located in city of Jam, Iran. They reported that there was a significant relationship between employees' job performance and mental health and any increase in mental health characteristics could help job performance. However, there was not any significant relationship between employees' job performance and their gender and there was no significant difference on mental health status in terms of gender. Lev-Ran et al. (2012) measured mental healthrelated QoL among individuals with anxiety disorders with and without concurrent cannabis implementation based on a US sample. Their results highlighted the relative importance of taking into account direct functional and emotional outcomes, as well as frequency of cannabis used, when evaluating the impact of cannabis implementation among individuals with anxiety disorders.

\section{The proposed study}

This paper presents a social work study to investigate the effects of employees' income and age on their mental health. The study considers the following two hypotheses,

1. There is a meaningful relationship between employee’s income and mental health.

2. There is a meaningful relationship between employee's age and mental health.

The study has accomplished among employees of Esfahan Steel company located in city of Esfahan, Iran. The sample size is calculated as follows,

$n=\frac{N \times z_{\alpha / 2}^{2} \times p \times q}{\varepsilon^{2} \times(N-1)+z_{\alpha / 2}^{2} \times p \times q}$,

where $N$ is the population size, $p=1-q$ represents the yes/no categories, $z_{\alpha / 2}$ is CDF of normal distribution and finally $\varepsilon$ is the error term. Since we have $p=0.5, z_{\alpha / 2}=1.96$ and $N=5528$, the number of sample size is calculated as $n=150$. The study uses a standard questionnaire originally developed by Goldberg and Williams (2000). The questionnaire contains different questions on Human Relations, Job security, Job progress, Working in partnership, Dignity, Balancing work and life, Work commitment and Financial status. Fig. 1 shows details of some personal charactersitics of the participants who took part in our survey.

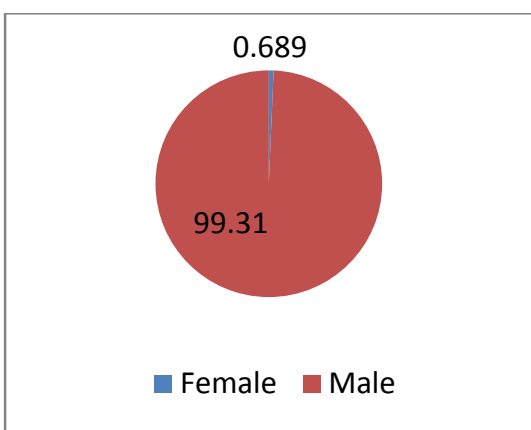

Gender

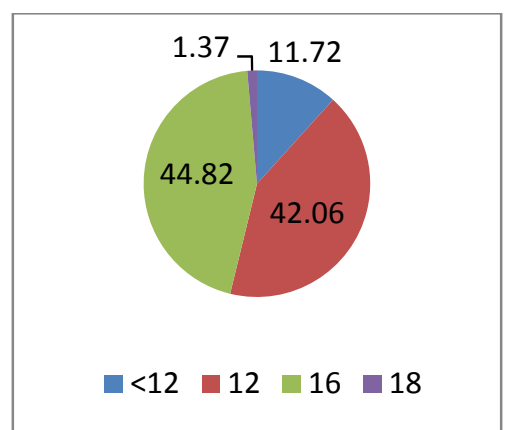

Years of education

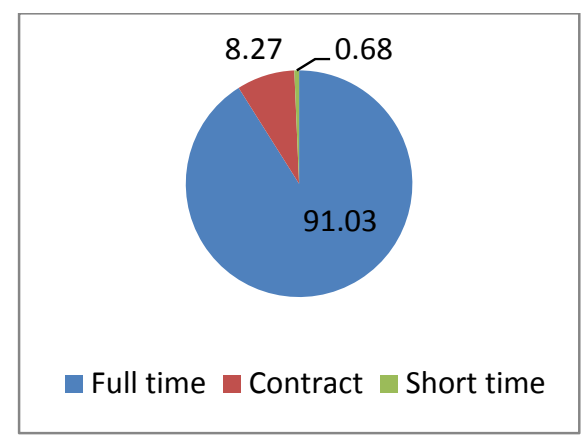

Employment

Fig. 1. Personal charactersitics of the participants 
As we can see from the results of Fig. 1, half of the participants had some university education and most of them were male and full time employees. Next, we present details of our findings on testing the hypotheses of the survey.

\section{The results}

\subsection{The first hypothesis: Relationship between mental health and income}

The first question of the survey is associated with the relationship between employees' mental health and their income. Table 1 demonstrates the results of ANOVA test between these two groups.

\section{Table 1}

The summary of ANOVA test on testing the relationship between mental health and income

\begin{tabular}{lccccc}
\hline Model & Sum of Squares & $\mathrm{df}$ & Mean of Squares & F-value & Sig. \\
\hline Regression & 1362.712 & 3 & 454.237 & 3.135 & .028 \\
Residual & 18834.131 & 130 & 144.878 & & \\
\hline Total & 20196.843 & 133 & & & \\
\hline
\end{tabular}

As we can observe from the results of Table 1, there is a meaningful relationship between employees' income and mental health. In other words, when the employees are supported by good benefit package, we may expect employee with better personal characteristics.

\subsection{The second hypothesis: Relationship between mental health and age}

The second question of the survey is associated with the relationship between employees' mental health and their age. Table 2 presents the summary of the results of ANOVA test between these two groups.

Table 2

The summary of ANOVA test on testing the relationship between mental health and age

\begin{tabular}{lccccc}
\hline Model & Sum of Squares & df & Mean of Squares & F-value & Sig. \\
\hline Regression & 17.958 & 2 & 8.979 & .058 & .943 \\
Residual & 20178.885 & 131 & 154.037 & & \\
\hline Total & 20196.843 & 133 & & & \\
\hline
\end{tabular}

As we can see from the results of Table 2, there is not any meaningful relationship between employees' age and mental health when the level of significance is five or even ten percent. This means age has no meaningful impact on mental health of employees who work for Esfahan Steel company.

\section{Conclusion}

In this paper, we have presented an empirical investigation to study the effects of employees' income and age on regular employees who worked for Esfahan Steel company. The results have indicated that while income played essential role on mental health, age did not statistically preserve any meaningful impact on employees' mental health. The results of the study are consist with findings earlier reported by Kamrani and Shafiabadi (2014) and Ghodrati, H \& Zargarzadeh, Z. (2013).

\section{Acknowledgement}

The authors would like to thank the annonymous referees for their comments on earlier version of this paper. We are also delighted for the cooperation of the officials of the Esfahan Steel Company. 


\section{References}

Ahmadi, P., Bakhshizadeh, A \& Balouchi, H. (2012). Studying the impact of mental health on job performance of managers and staff. Management Science Letters, 2(5), 1579-1588.

Baba, V. V., Galperin, B. L., \& Lituchy, T. R. (1999). Occupational mental health: A study of workrelated depression among nurses in the Caribbean. International Journal of Nursing Studies, 36(2), 163-169.

Brackbill, R. M., Stellman, S. D., Perlman, S. E., Walker, D. J., \& Farfel, M. R. (2013). Mental health of those directly exposed to the World Trade Center disaster: Unmet mental health care need, mental health treatment service use, and quality of life. Social Science \& Medicine, 81, 110-114.

Ghodrati, H \& Zargarzadeh, Z. (2013). A study on the relationship between employee mental health and agility strategic readiness: A case study of Esfahan hospitals in Iran. Management Science Letters, 3(4), 1095-1104.

Goldberg, D., \& Williams, P. (2000). General health questionnaire (GHQ). Swindon, Wiltshire, UK: NFER Nelson.

Kamrani, A \& Shafiabadi, A. (2014). Investigating the relationship between quality of life and mental health: A case study of steel industry. Management Science Letters, 4(5), 1059-1062.

Levinson, H., Price, C. R., Munden, K. J., \& Solley, C. M. (1962). Men, Man agement and Mental Health. Cambridge, MA: Harvard University Press.

Lev-Ran, S., Le Foll, B., McKenzie, K., \& Rehm, J. (2012). Cannabis use and mental health-related quality of life among individuals with anxiety disorders. Journal of anxiety disorders, 26(8), 799810.

Robbins, S.P. (2001). Organizational Behaviour. New Delhi, Prentice Hall, Inc. 